\title{
Epidemiological study of farmer's lung in five districts of the French Doubs province
}

\author{
A DEPIERRE, J C DALPHIN, D PERNET, A DUBIEZ, C FAUCOMPRÉ, J L BRETON \\ From the Department of Chest Diseases, Centre Hospitalier, Universitaire de Besançon, Besançon, France
}

ABSTRACT The prevalence of farmer's lung was studied in five districts of the French Doubs province (Rougemont, Clerval, Levier, Montbenoît, Mouthe) on the basis of a medical and occupational questionnaire and serological studies for precipitins. Of the 1763 active farmers (response rate $69 \%$ ) who participated in the study, 270 were suspected of having farmer's lung and divided, on the basis of clinical and serological criteria, into probable and possible farmer's lung groups. This subgroup of 270 patients was examined in more detail with physical examination, chest radiographs, and pulmonary function tests. Probable farmer's lung was diagnosed in 77 cases (53 men and 24 women, mean age 51.7 years), a prevalence of $43 \cdot 7 / 1000$. Possible farmer's lung was present in a further 193 subjects. Fever was the most specific symptom. In the group with probable farmer's lung the frequency of crepitations, restrictive ventilatory defect, and radiological interstitial abnormalities was $21.5 \%, 9.5 \%$, and $9.2 \%$ at the time of the study. Farmer's lung was more common in the middle tablelands than in the plain or mountain areas $(\mathrm{p}<0.01)$. The difference in prevalence of farmer's lung between the Mouthe mountain and Levier middle tableland districts $(25 \cdot 2 / 1000$ and 60·8/1000) raises the possibility that cold may protect against the disease. Farmer's lung was more frequent in men and in the age group 51-55 years. Among possible occupational factors, only regular work connected with feeding animals was associated with a significant risk (odds ratio 2.55 with a $95 \%$ confidence interval of 1.09-5.93). The frequency of chronic bronchitis in the population studied was $14 \cdot 8 \%$. There was a close link between farmer's lung and chronic bronchitis, $50 \cdot 6 \%$ of patients with probable farmer's lung having it but only $8.6 \%$ of patients without farmer's lung ( $p<0.001$ ). In patients with probable farmer's lung chronic bronchitis was independent of smoking and age. There were fewer smokers in the probable farmer's lung than in the non-farmer's lung group ( $p<0.05$ ).

\section{Introduction}

Farmer's lung is one of the most common forms of extrinsic allergic alveolitis. It usually occurs in farmers exposed to various mouldy plant materials, notably hay. Its prevalence in farming populations changes from one region to another, with estimated figures varying from around $0.5 \%{ }^{12}$ to more than $5 \% .^{34}$ These differences are due to climatic variations from one region to another and to differences in agricultural practices. Nevertheless, the characteristics of farms and certain agricultural practices-in particular the method of drying and storage of fodder that may be linked with the development of farmer's lung antigens-have not been extensively studied.

Address for reprint requests: Professor A Depierre, Department of Chest Diseases, Centre Hospitalier, Universitaire de Besançon, 2 place Saint Jacques, 25000 Besançon, France.

Accepted 22 February 1988
Diagnostic criteria for farmer's lung for epidemiological studies are difficult to establish. Proof of exposure to antigen and the existence of typical symptoms are necessary. Typical radiological signs and deterioration in pulmonary function values may well have disappeared by the time of the study. Inclusion of abnormal results of investigations such as these as obligatory diagnostic criteria carries the risk of underestimating the prevalence of farmer's lung. The implications of serum precipitins against farmer's lung antigens remain controversial. Their presence may be diagnostically useful but epidemiological studies have shown that from $5 \cdot 6 \%^{5}$ to $30 \%{ }^{6}$ of apparently healthy agricultural workers have precipitins against farmer's lung antigens.

Chronic obstructive lung disease is common in agricultural populations. Heller ${ }^{7}$ and Babbott $^{8}$ showed that dairy farmers, especially non-smokers, had a higher prevalence of symptoms of chronic bronchitis and a lower $\mathrm{FEV}_{1} / \mathrm{VC}$ (forced expiratory volume in 
one second/vital capacity) ratio than controls from an industrial background. A link between chronic obstructive lung disease and farmer's lung or farmer's lung antigen is possible, in particular in dairy farmers.

The main aim of the present study was to evaluate the prevalence of farmer's lung in five districts of the French Doubs province, with estimation of certain occupational risk factors. A second aim was to identify chronic bronchitis in a rural context, seeking a possible link with farmer's lung.

\section{Methods}

The Doubs is a rural province situated on the Swiss border, at the foot of the Jura mountains. It includes three levels, with altitudes ranging from 200 to 1400 metres. Its climate is continental. Spring and early summer are damp. Mean annual rainfall varies from 1300 to $2000 \mathrm{~mm}$. Agricultural production consists almost exclusively of milk and the raising of cattle.

The study was carried out in five districts of the Doubs (Rougemont, Clerval, Levier, Montbenoit, and Mouthe). Rougemont is situated in the plain; Clerval, Levier, and Montbenoît in the middle tablelands, and Mouthe at mountain altitude.

All working dairy farmers in these five districts were contacted and asked to fill in a questionnaire and provide a blood sample. Ten days after being sent out by mail, questionnaires were collected at the time of visits near to the farms of the subjects. These questionnaires were then reviewed by the same trained agent (DP). All subjects provided a blood sample, which was tested for the presence of precipitins. One thousand seven hundred and sixty three of the 2555 farmers in the five districts $(69 \%)$ agreed to participate in the study. Table 1 shows response rates and the mean age and sex of the subjects studied by district. This study population was representative of the agricultural population of the five districts with regard to age and sex and the characteristics of the farms.

The questionnaire covered personal and demographic information, smoking habits, respiratory past history, an inventory of recent respiratory symptoms, and, finally, occupational information (size of cattle herd, quantification of work concerned with animal feeding, method of drying and storage of fodder). Questions concerning respiratory symptoms were drawn up and based broadly on the questionnaire of the American Thoracic Society. ${ }^{9}$

Serum from each patient was analysed by both double diffusion ${ }^{10}$ and immunoelectrophoresis (Professor J M Aiache, Immunoallergology $\vec{\circ}$ Laboratory, Clermont-Ferrand, France). Detection antigens consisted of Micropolyspora faeni and three extracts of mouldy hay from the Doubs - one each from the plain, the middle tablelands and the mountain area." Only sera from patients with respiratory symptoms, regardless of their nature, were analysed. Serological results were regarded as positive $(\mathbf{S}+)$ when there was at least one precipitation arc to at least one of the four antigen extracts, either by double diffusion or immunoelectrophoresis. The results were described as strongly positive $(\mathbf{S}++)$ when there were at least two precipitation arcs to at least two different antigen extracts.

CRITERIA USED TO DIAGNOSE FARMER'S LUNG Individuals in the population were categorised on the basis of their symptoms (as given in the questionnaire) and of the results of serology as having "probable farmer's lung" or "possible farmer's lung."

\section{"Possible farmer's lung"}

Obligatory criteria were: (1) probable exposure to mouldy hay and (2) a recent history of bouts of dry cough and shortness of breath without wheezing, with or without fever, occurring after exposure to mouldy hay between the beginning of October and the end of May.

Temperature was not measured; episodes of fever were accepted from the history of the patients.

"Probable farmer's lung"

Individuals were considered as having probable far- $D$ mer's lung when in addition to the obligatory criteria (1) and (2) they fulfilled conditions $(a)$ or $(b)$-namely: N

(a) a consistent delay of four to eight hours between exposure to antigen and the onset of

Table 1 Number of dairy farmers, number of dairy farmers studied, response rate, mean age, and sex by district

\begin{tabular}{|c|c|c|c|c|c|}
\hline & Dairy farmers & $\begin{array}{l}\text { Dairy farmers } \\
\text { studied }\end{array}$ & Response rate (\%) & Mean age (y) & $\operatorname{Sex}(M / F)$ \\
\hline $\begin{array}{l}\text { Clerval } \\
\text { Levier } \\
\text { Montbenoît } \\
\text { Mouthe } \\
\text { Rougemont } \\
\text { Total }\end{array}$ & $\begin{array}{r}454 \\
682 \\
640 \\
422 \\
357 \\
2555\end{array}$ & $\begin{array}{r}320 \\
477 \\
470 \\
278 \\
218 \\
1763\end{array}$ & $\begin{array}{l}70 \cdot 5 \\
69 \cdot 9 \\
73 \cdot 4 \\
65 \cdot 9 \\
61 \cdot 1 \\
69\end{array}$ & $\begin{array}{l}47 \\
47 \\
47 \\
47 \\
49 \\
47\end{array}$ & $\begin{array}{l}168 / 152 \\
265 / 212 \\
259 / 211 \\
163 / 115 \\
122 / 96 \\
977 / 786\end{array}$ \\
\hline
\end{tabular}


respiratory symptoms and positive serological results $(\mathbf{S}+)$; or

(b) when the interval between antigen exposure and respiratory symptoms could not be definitely established, the following were required:

- progressive dyspnoea worsening in winter (October to May) during the period of indoor housing of animals

-recrudescence of respiratory symptoms after each exposure to mouldy hay

- serological results strongly positive $(\mathbf{S}++)$.

All other subjects were described as "non-farmer's lung." Chronic bronchitis was defined as cough and daily expectoration for three months of the year for two consecutive years.

\section{SUBSEQUENT EXAMINATION}

All those with probable or possible farmer's lung were asked to attend the department of respiratory diseases at the Besançon Teaching Hospital Centre for physical examination, respiratory function testing and chest radiography. Clinical examination was limited to listening for crepitations and was carried out by the same respiratory disease specialist (JCD) throughout the study period.

A spirometer (Autospiro Minato AS 500:Minato Medical Science Company Limited, Osaka, Japan) was used to measure vital capacity (VC) and forced expiratory volume in one second $\left(\mathrm{FEV}_{1}\right)$. The spirometer was calibrated before the study started and at intervals throughout with a one litre syringe. A minimum of three satisfactory records for $\mathrm{FEV}_{1}$ and FVC was obtained for each subject, and the best of them was selected, after correction to BTPS conditions. All records were obtained by the same trained technician (DP). Values were expressed as percentages of the normal values of the European Coal and Steel Community. Subjects were said to have a restrictive ventilatory defect when their vital capacity was less than $80 \%$ of their predicted value with a normal $\mathrm{FEV}_{1} /$

Table 2 Farmer's lung symptoms and chronic bronchitis in the total population of dairy farmers

\begin{tabular}{lrc}
\hline & No & $\%$ \\
\hline $\begin{array}{lr}\text { Respiratory symptoms after contact } \\
\text { with mouldy hay }\end{array}$ & 216 & $12 \cdot 3$ \\
$\begin{array}{l}\text { Cough } \\
\text { Dyspnoea }\end{array}$ & 124 & 7 \\
Fever & 124 & 7 \\
Typical farmer's lung symptoms* & 0 & - \\
Cough & 54 & $3 \cdot 1$ \\
Dyspnoea & 54 & $3 \cdot 1$ \\
Fever & 54 & $3 \cdot 1$ \\
Chronic bronchitis & 32 & $1 \cdot 8$ \\
\hline * Respiratory symptoms 4-8 hours after contact with mouldy hay.
\end{tabular}

$\mathrm{VC}$ ratio, and an obstructive ventilatory defect when their $\mathrm{FEV}_{\mathrm{l}} / \mathrm{VC}$ ratio was less than $75 \%$ of the predicted value.

A chest radiograph was obtained and all were interpreted by the same trained respiratory disease specialist (AD). Radiological appearances were divided into four groups in agreement with Hapke ${ }^{12}$ and Monkäre ${ }^{13}$ : ground glass appearance, nodular opacities, striated patchy opacities, and fibrosis.

\section{STATISTICAL ANALYSIS}

Values are expressed as means with standard deviations in parentheses. In the comparison of groups for qualitative values the $\chi^{2}$ test was used and for mean values the Student's $t$ test. Risk factors are expressed by the odds ratio and its $95 \%$ confidence interval.

\section{Results}

Two hundred and sixteen subjects (12.3\%) had respiratory symptoms after manipulating mouldy hay. Fifty four $(3 \cdot 1 \%)$ had respiratory symptoms consistent with farmer's lung, with cough and dyspnoea without wheezing four to eight hours after the handling of mouldy hay. Fever was present in $59 \%$ of cases where respiratory symptoms were typical, and it was found only when respiratory manifestations were delayed. The frequency of chronic bronchitis in the population was $14.8 \%$ (table 2). Of the subjects with respiratory symptoms, $72.6 \%$ had at least one arc of precipitation $(\mathrm{S}+)$ and $36.4 \%$ had a strongly positive serological result $(\mathbf{S}++)$.

Probable farmer's lung was diagnosed in 77 subjects (4.37\%), 53 men and 24 women. Ages ranged from 32 to 65 (mean 51.7 (SD 11.7)) years. The prevalence of probable farmer's lung in this population was 43.7 / 1000. On the basis of the definition given above there were 193 cases of possible farmer's lung, 115 men and

Table 3 Crepitations, reduced pulmonary function and radiological changes in subjects with probable and possible farmer's lung

\begin{tabular}{|c|c|c|}
\hline & $\begin{array}{l}\text { Probable } \\
\left(n=65^{*}\right)\end{array}$ & $\begin{array}{l}\text { Possible } \\
\left(n=154^{*}\right)\end{array}$ \\
\hline & No $(\%)$ & No $(\%)$ \\
\hline $\begin{array}{l}\text { Physical examination } \\
\text { Inspiratory crepitations }\end{array}$ & $14 \quad(21 \cdot 5)$ & $(7 \cdot 8)$ \\
\hline $\begin{array}{l}\text { Pulmonary function } \dagger \\
\text { Restrictive defect } \\
\text { Obstructive defect } \\
\text { Data not available }\end{array}$ & $\left.\begin{array}{r}6 \\
18 \\
2\end{array}\right\} \quad(38 \cdot 1)$ & $\left.\begin{array}{r}8 \\
15 \\
0\end{array}\right\} \quad(14 \cdot 9)$ \\
\hline $\begin{array}{l}\text { Radiological changes } \\
\text { Ground glass appearance } \\
\text { Nodular } \\
\text { Striated patchy opacities } \\
\text { Fibrosis }\end{array}$ & $\left.\begin{array}{l}2 \\
1 \\
1 \\
2\end{array}\right\}(9 \cdot 2)$ & $\left.\begin{array}{l}2 \\
2 \\
0 \\
0\end{array}\right\}(2 \cdot 6)$ \\
\hline
\end{tabular}

* Number of subjects who accepted further examination.

†Restrictive defect-FVC below $80 \%$ predicted; obstructive defect $-F E V_{1} / F V C$ ratio below $75 \%$ predicted. 
Table 4 Prevalence of probable farmer's lung by district and in total population

\begin{tabular}{|c|c|c|}
\hline \multirow[b]{2}{*}{ District } & \multicolumn{2}{|c|}{ Probable cases } \\
\hline & No & Rate/1000 \\
\hline $\begin{array}{l}\text { Plain: } \\
\text { Rougemont }\end{array}$ & 4 & $18 \cdot 3$ \\
\hline $\begin{array}{l}\text { Middle tablelan } \\
\text { Clerval } \\
\text { Levier } \\
\text { Montbenoît }\end{array}$ & $\begin{array}{l}15 \\
29 \\
22\end{array}$ & $\left.\begin{array}{l}46 \cdot 9 \\
60 \cdot 8 \\
49 \cdot 8\end{array}\right\} 52 \cdot 1^{*}$ \\
\hline $\begin{array}{l}\text { Mountain: } \\
\text { Mouthe }\end{array}$ & 7 & $25 \cdot 2$ \\
\hline Total & 77 & 43.7 \\
\hline
\end{tabular}

* $\mathrm{p}<0.01$ ( $\chi^{2}$ test)-middle tableland $v$ plain, mountain, and both.

78 women, their ages ranging from 18 to 65 (mean 48.9 (SD 13.7)) years.

Sixty five patients with probable farmer's lung $(84 \%)$ and 154 with possible farmer's lung $(80 \%)$ accepted further hospital investigations (table 3 ). Among those with probable farmer's lung $14(21 \%)$ had crepitations on auscultation and 24 (38\%) pathological respiratory function test results, six with a restrictive ventilatory defect and 18 with an obstructive ventilatory defect. Six patients $(9 \%)$ had radiological changes compatible with farmer's lung.

The prevalence of farmer's lung in the five districts, divided into the plain (Rougemont), middle tablelands (Clerval, Levier, Montbenoît), and mountain country (Mouthe), are compared in table 4 . The prevalence was greatest in the middle tableland districts $(52 \cdot 1 /$ $1000)$, being highest in the Levier district $(60 \cdot 8 / 1000)$. The prevalence in the plain was $18 \cdot 3 / 1000$ and in the mountain area $25 \cdot 2 / 1000$. In the tablelands it was significantly different from the prevalence in the other two areas, both separately and in combination.

Farmer's lung was more frequent among men (54.2/ Table 5 Comparison of farmers with probable farmer's lung and non-farmer's lung patients for hay exposure, size of dairy herd, and type of drying and storage of hay

\begin{tabular}{|c|c|c|}
\hline & $\begin{array}{l}\text { Probable farmer's lung } \\
(n=77)\end{array}$ & $\begin{array}{l}\text { Non-farmer's lung } \\
(n=1493)\end{array}$ \\
\hline & No (\%) & No (\%) \\
\hline $\begin{array}{l}\text { Exposure to hay: } \\
\text { Animal feeding } \\
\text { Number of dairy cattle: } \\
<40 \\
40-60 \\
>60 \\
\text { Type of drying and } \\
\text { storage of hay: } \\
\text { Rectangular bales } \\
\text { Round bales } \\
\text { In bulk } \\
\text { In bulk with artificial } \\
\text { drying }\end{array}$ & $\begin{array}{l}71^{*}(92 \cdot 2) \\
(\mathrm{n}=74) \\
22 \quad(29 \cdot 7) \\
25(33 \cdot 8) \\
27 \quad(36 \cdot 5) \\
\\
(\mathrm{n}=77) \\
47(61) \\
10(13) \\
16(20 \cdot 8) \\
8 \quad(10 \cdot 4)\end{array}$ & $\begin{array}{l}1228(82 \cdot 2) \\
(\mathrm{n}=1408) \\
395(28 \cdot 1) \\
485(34 \cdot 2) \\
531(37 \cdot 7) \\
\\
(\mathrm{n}=1380) \\
791(57 \cdot 3) \\
175(12 \cdot 7) \\
280(20 \cdot 3) \\
169(12 \cdot 2)\end{array}$ \\
\hline
\end{tabular}

Table 6 Comparison of smoking habits and chronic bronchitis in probable farmer's lung, possible farmer's lung, and non-farmer's lung

\begin{tabular}{|c|c|c|c|}
\hline & $\begin{array}{l}\text { Probable } \\
(n=77)\end{array}$ & $\begin{array}{l}\text { Possible } \\
(n=193)\end{array}$ & $\begin{array}{l}\text { Non- } \\
\text { farmer's lung } \\
(n=1493)\end{array}$ \\
\hline & No (\%) & No (\%) & No $(\%)$ \\
\hline $\begin{array}{l}\text { Smokers } \\
\text { Bronchitis } \\
\text { Ex-smokers } \\
\text { Bronchitis } \\
\text { Never smokers } \\
\text { Bronchitis }\end{array}$ & $\begin{array}{c}12 *(15 \cdot 6) \\
6 \dagger(50) \\
14(18 \cdot 2) \\
7 \neq(50) \\
51(66 \cdot 2) \\
26 \neq(51)\end{array}$ & $\begin{array}{c}30 *(15 \cdot 5) \\
22 \dagger(73 \cdot 3) \\
31(16 \cdot 1) \\
14 \ddagger(45 \cdot 2) \\
132(68 \cdot 4) \\
57 \ddagger(43 \cdot 2)\end{array}$ & $\begin{array}{c}335(22 \cdot 4) \\
63(18 \cdot 8) \\
222(14.9) \\
11(5) \\
936(62 \cdot 7) \\
55(5.9)\end{array}$ \\
\hline $\begin{array}{l}\text { Total } \\
\text { Bronchitis }\end{array}$ & $39 \ddagger(50 \cdot 6)$ & $93 \mp(48 \cdot 2)$ & $129(8 \cdot 6)$ \\
\hline
\end{tabular}

*p $<0.05 ;$ tp $<0.01 ; \ddagger \mathrm{p}<0.001\left(\chi^{2}\right.$ test); comparisons are: probable farmer's lung $v$ non-farmer's lung and possible farmer's lung $v$ non-farmer's lung.

$1000 ; \mathrm{p}<0.05)$ and the peak prevalence was in the age $\vec{c}$ group 51-55 years $(72 / 1000 ; \mathrm{p}<0.01)$; there were no cases under the age of 30 .

All the subjects studied were farmers engaged in cattle raising. Study of occupational factors showed that there was a greater risk for farmers who regularly provided fodder for animals (odds ratio $2 \cdot 55,95 \%$ confidence interval 1.09-5.93; table 5).

There was evidence of a close link between chronic bronchitis and farmer's lung: $50.6 \%$ of patients with probable farmer's lung and $48.2 \%$ of those with possible farmer's lung had symptoms of chronic bronchitis, compared with $8.6 \%$ of the non-farmer's lung group (table 6). This association was independent of smoking as it was still present when the three groups were compared in terms of smoking habit. Chronic bronchitis did not appear to be linked to smoking in the probable farmer's lung group as chronic bronchitics occurred in $50 \%$ of smokers, in $50 \%$ of exsmokers, and in $51 \%$ of non-smokers. In the nonfarmer's lung group, however, chronic bronchitis was linked to smoking. Mean age and distribution by age group were the same in the patients with chronic

Table 7 Summary of farmer's lung prevalence in published reports

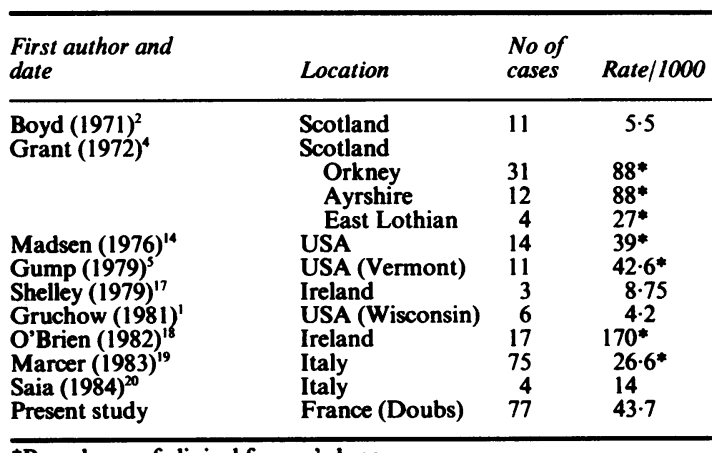

*Prevalence of clinical farmer's lung. 
bronchitis and probable farmer's lung as in the probable farmer's lung group as a whole. The prevalence of chronic bronchitis among patients with probable farmer's lung was invariably around $50 \%$, regardless of age. Finally, smokers were less frequent in the farmer's lung group $(15.6 \%, \mathrm{p}<0.05$ versus non-farmer's lung).

\section{Discussion}

The overall response rate to the questionnaire of $69 \%$ was satisfactory, although we could not obtain medical information on non-responders. The prevalence of probable farmer's lung was $43 \cdot 7 / 1000$ in the population studied. This prevalence rate was high, similar to the rates found in Scotland ${ }^{4}$ and in certain regions of the United States. ${ }^{514}$

The link between the frequency of farmer's lung and rainfall during haymaking is well established. ${ }^{241516}$ This explains the frequency of farmer's lung in the Doubs, which has a high annual rainfall and many rainy days during the haymaking season ( 24 days' rainfall on average from 15 May to 15 July over the past 10 years, according to Besançon Meteorological Centre). Caution, however, is required in the interpretation of results that are dependent on the methods used and above all on the diagnostic criteria.

Table 7 shows that the highest prevalence rates were obtained on the basis of clinical diagnostic criteria only, with no account taken of the results of special investigations. The prevalence of clinical farmer's lung found by Grant ${ }^{4}$ in Scotland fell by half when a positive serological result was required. $\mathrm{O}^{\prime}$ Brien $^{18}$ in Ireland reported a clinical disease prevalence of 170 / 1000 , yet in the same region Shelley ${ }^{17}$ found a prevalence of only $8 \cdot 75 / 1000$ when strict criteria, including delayed respiratory symptoms and serological or radiological confirmation, were required. These facts clearly illustrate the difficulty in establishing diagnostic criteria for farmer's lung in prevalence studies. The delayed nature of symptoms is the essential diagnostic feature, but this may be difficult to establish and confusion with the organic dust toxic syndrome or late asthmatic reactions is possible. Description of symptoms in the present study showed that fever was the most specific symptom. It was present only when respiratory manifestations were delayed and was never present when they occurred immediately or soon after exposure to mouldy hay.

Results of special investigations showed that the frequency of auscultation and radiological abnormalities was low in those with probable farmer's lung. Such results were not surprising as special investigations were carried out in patients irrespective of any recent change in symptoms, and radiological abnor- malities, with the exception of fibrosis, would be expected to disappear fairly quickly after exposure. The frequency of spirometric abnormalities in patients with probable farmer's lung was higher. These results are identical with those of Grant, ${ }^{4}$ who found eight of 43 patients with a restrictive pattern, 12 with airflow obstruction, three with a mixed pattern, and only three with radiological appearances suggesting acute alveolitis. Probably spirometric abnormalities persist longer, after acute radiological abnormalities have disappeared. Even during the acute illness radiological abnormalities are less common and less striking than pulmonary function disturbances. ${ }^{21}$

Analysis of individual factors showed a higher risk for men, confirming that farmer's lung is predominantly a male disease $\mathrm{e}^{22}$ as a result of more exposure to antigen among men.

Absence of any cases before the age of 30 and the frequency of the condition in the 51-55 year age group suggests that the duration of antigen exposure is important. Among the occupational factors studied, only work that included the feeding of animals was found to be accompanied by any significant risk. The "animal feeding" characteristic was applied to farmers regularly engaged in giving fodder to their animals (at least three times a week). In addition, three out of six farmers with farmer's lung had discontinued providing fodder for their animals because of their respiratory symptoms. This confirms that regular work concerned with the feeding of animals is the essential occupational risk. No other occupational factors seemed to be important. There was no evidence that the size of the cattle herd or methods of drying and storage of fodder had any influence.

Dampness of fodder and rainfall during the haymaking season are important factors and one of the reasons for the higher frequency of farmer's lung in the middle tablelands found in the present study. The large difference in prevalence between the Levier and Mouthe districts, however, is of particular interest. These two districts are adjacent and their agricultural populations identical in terms of individual characteristics (age, sex ratio-table 1) and occupation ("animal feeding"). Mean annual rainfall, rainfall during haymaking, and the number of rainy days during haymaking were also identical. The only differences are altitude, greater at Mouthe $(1000$ $1460 \mathrm{~m})$ than at Levier $(700-1000 \mathrm{~m})$, and temperature, cooler at Mouthe than at Levier with a mean annual difference ranging from $3^{\circ} \mathrm{C}$ to $6^{\circ} \mathrm{C}$, depending on the years considered (Besançon Meteorological Centre). Cold might impede the development of actinomycetes in barn stored fodder.

The frequency of chronic bronchitis was high $(14.8 \%)$ in this population as in other studies. ${ }^{724}$ This has been attributed to the multiplicity of respiratory 
pollutants to which farmers are exposed: organic and inorganic dusts, fertilisers, pesticides, and gasoline and diesel vapours. In the present study, however, chronic bronchitis was closely linked with farmer's lung. The fact that chronic bronchitis was independent of smoking only in the probable farmer's lung group, and was related to tobacco in the usual way in the patients without farmer's lung, further emphasises the link between the two conditions. Because of possible confusion ${ }^{22} 25$ between symptoms of farmer's lung and chronic bronchitis we paid particular attention to questions concerning chronic bronchitis and farmer's lung. In the light of our results, we suggest that farmer's lung and chronic bronchitis in farmers, particularly non-smokers, have a common aetiological factor (organic dusts). Such rural, tobacco independent chronic bronchitis could be of immunoallergic origin, as suggested by several histopathological reports on acute farmer's lung. These have shown bronchiolar abnormalities, obstructive exudative bronchitis with vascular congestion, and sometimes plasmocytes and antigen deposits. ${ }^{212326}$

In epidemiological studies, where data depend on the memory of the subjects, it is difficult to be confident about information recalled about the onset of symptoms and their chronology, particularly when there is concomitant evaluation of an acute or subacute disease (farmer's lung) and a usually chronic disease (chronic bronchitis). In the present study, however, the prevalence of chronic bronchitis by age group closely followed that of farmer's lung. The closeness of this relation suggests a simultaneous onset of the two conditions, and strengthens the suggestion of a similar pathogenetic mechanism. The frequency of chronic bronchitis in patients with farmer's lung, its close link with farmer's lung and similar natural history, the absence of smoking as an aetiological factor, and the pathological characteristics of the bronchial disease in acute or subacute forms of farmer's lung suggest that chronic bronchitis in these subjects is very different from the usual form of tobacco related chronic bronchitis, even though the two conditions fit the same definition of cough and chronic expectoration.

Farmer's lung was more common in non-smokers, confirming several similar reports. ${ }^{13527}$ There are four possible hypotheses: (1) a protective effect of cigarette smoke against farmer's lung; (2) a tendency for subjects with respiratory intolerance to plant dusts not to smoke; (3) a tendency for subjects with bronchial manifestations linked to smoking to expose themselves less to plant dusts; (4) previous tobacco related illness, rendering certain subjects ineligible or nonresponders.

This study has determined the frequency of farmer's lung in damp and mountainous rural regions. Cold may have a protective role, and a current $\underset{\vec{\rho}}{\vec{\rho}}$ microbiological study of fodder in the two areas may $\frac{\mathscr{T}}{2}$ help to clarify this point. No new occupational factors were identified. We confirmed the frequency of chronic $\frac{\bar{\sigma}}{\bar{\omega}}$ bronchitis in this rural area, particularly among non- $\frac{\widehat{\Phi}}{\Phi}$ smokers. Its close link with farmer's lung and evidence $\varrho$ of a similar immunoallergic mechanism suggest that is the aetiological factors responsible for chronic obs- $\overrightarrow{0}$ tructive lung disease may need to be reconsidered.

We are grateful for cooperation and support from $\stackrel{\circ}{\rightleftharpoons}$ Professor J M Aiache, Professor H Allemand, Depart- $\underset{x}{ }$ ment of Epidemiology, Centre Hospitalier Régional $\vec{\omega}$ de Besançon; Drs J J Laplante and A Bichon, medical os department of the Mutualité Sociale Agricole du Doubs; and J Raison, director of Assurances $\circ$ Mutuelles Agricoles de Bourgogne-Franche-Comté. 근

\section{References}

1 Gruchow HW, Hoffmann RG, Marx JJ Jr, Emanuel DA, $\stackrel{\oplus}{\oplus}$ Rimm AA. Precipitating antibodies to farmer's lung $\infty$ antigens in a Winsconsin farming population. Am Rev Respir Dis 1981;124:411-5.

2 Boyd DHA. The incidence of farmer's lung in Caithness. Scot Med J 1971;16:261-2.

3 Morgan DC, Smyth JT, Lister RW, et al. Chest symp- 을 toms in farming communities with special reference to farmer's lung. Br J Ind Med 1975;32:228-34.

4 Grant IWB, Blyth W, Wardrop VE, Gordon RM, Pearson JCG, Mair A. Prevalence of farmer's lung in Scotland: a pilot survey. $\mathrm{Br}$ Med J 1972;i:530-4.

5 Gump DW, Babbott FL, Holly C, Sylwester DL. Farmer's lung disease in Vermont. Respiration 1979;37:5260.

6 Wardrop VE, Blyth W, Grant IWB. Farmer's lung in a group of Scottish dairy farms. $\mathrm{Br} J$ Ind Med 1977;34:186-95.

7 Heller RF, Hayward DM, Farebrother MTB. Lung function of farmers in England and Wales. Thorax 1986;41:117-21.

8 Babbott FL, Gump DW, Sylwester DL, MacPherson BV, \ Holly C. Respiratory symptoms and lung function in a 을 sample of Vermont dairymen and industrial workers. $\mathrm{N}$ Am J Public Health 1980;70:241-5.

9 Ferris BG. Epidemiology standardization project. $A m \mathrm{~N}$ Rev Respir Dis 1978;118(suppl):7-55.

10 Ouchterlony $O$. Diffusion-in-gel method for immuno- $\omega$ logical analysis. In: Kaillos P, ed. Progress in allergy. Basel: Karger, 1958:1.

11 Aiache JM, Jeanneret A, Molina CL, Morell-Brotard F, Bihet P. Méthodes de diagnostic immunologique des $\stackrel{?}{-}$ alvéolites extrinsèques. Cah Med 1977;3:651-62.

12 Hapke EJ, Seal RME, Thomas GO. Farmer's lung: a clinical, radiographic and serological correlation of $\mathbb{\Phi}$ acute and chronic stages. Thorax 1968;23:451-68.

13 Monkäre S, Ikonen M, Haatel A. Radiologic finding in 음 farmer's lung. Chest 1985;87:460-6.

14 Madsen D, Klock LE, Wenzel FJ, Robbins JC, Schmidt $\bigcirc$ $\mathrm{CH}$. The prevalence of farmer's lung in an agriculturate 
population. Am Rev Respir Dis 1976;113:171-4.

15 Staines FH, Forman JAS. A survey of “Farmer's lung”. J Coll Gen Pract 1961;4:351-82.

16 Terho EO, Heinonen OP, Lammi S. Incidence of farmer's lung leading to hospitalization and its relation to meteorological observations in Finland. Acta Med Scand 1983;213:295-8.

17 Shelley E, Dean G, Collins D, Dinah F, Evans J, MacHardy J. Farmer's lung: a study in North-West Ireland. Journal of the Irish Medical Association 1979;72:261-4.

18 O'Brien J, Dean G. Farmer's lung disease: an evaluation of Health education in the North-West of Ireland. Ir Med J 1982;75:352-61.

19 Marcer G, Simioni L, Saia B, Saladino G, Gemignani C, Mastrangelo G. Study of immunological parameters in farmer's lung. Clin Allergy 1983;13:443-9.

20 Saia B, Mastrangelo G, Marcer G, Reggio O. Prevalence and risk factors of chronic respiratory disease in a farming population. Med Lav 1984;75:101-9.
21 Emanuel DA, Wenzel FJ, Bowerman CI, Lawton BR. Farmer's lung: clinical, pathologic and immunologic study of twenty four patients. Am J Med 1964;37:392401.

22 Emanuel DA, Kryda MJ. Farmer's lung disease. Clin Rev Allergy 1983;1:509-32.

23 Molina CL. Alvéolites allergiques. In: Molina C, ed. Immunopathologie broncho-pulmonaire. Paris: Masson, 1984:55-143.

24 Pariente R, Couland C, Martin JP, Berthet CI, Baldeyrou $P$, Touaty E. Enquête sur les broncho-pneumopathies chroniques en milieu agricole (Eure, France). Rev Fr Mal Respir 1979;7:633-8.

25 Dyer EL. Farmer's lung: industrial hazard for rural inhabitants. South Med J 1980;73:353-61.

26 Seal RME, Hapke EJ, Thomas GO, Meek JC, Hayes M. The pathology of the acute and chronic stages of farmer's lung. Thorax 1968;23:469-89.

27 Warren CP. Extrinsic allergic alveolitis: a disease commoner in non-smokers. Thorax 1977;32:567-9. 